\section{Don't become a burden and don't complain: a case study of older persons suffering from incurable cancer and living alone in rural areas}

\author{
Guri Bitnes Wiik, ${ }^{1}$ Siri Devik, ${ }^{2}$ \\ Ove Hellzen ${ }^{1,3}$
}

${ }^{1}$ Faculty of Health and Science, NordTrondelag University College; ${ }^{2}$ Namsos Community Health Care; District west/unit Otteroy, Namsos; ${ }^{3}$ Centre for Care Research, Mid-Norway, Steinkjer, Norway

\section{Abstract}

The majority of older people wish to continue to live at home for as long as possible. As a consequence, the healthcare system, including cancer care, is located in urban areas and people living in rural areas must commute to gain access to the services offered. The aim of this study was to investigate how older people, who live on their own, experience living with incurable cancer and commuting for palliative care in rural Norway. A case study was designed and informants were recruited not because they were typical but because they were deemed to have the potential to contribute to knowledge about the phenomenon of being an older person who has been diagnosed with incurable cancer and lives alone in a rural area.

Three major categories were identified: "Hovering between hope and fear, Stressful commuting to palliative care, and Being exhausted. The findings indicated that older people who have been stricken with incurable cancer and who live alone in rural areas have to walk the palliative path alone. A common feature of all the informants is that they do not speak out and they do not complain. Even though the trend in healthcare is towards centralized treatment, shorter and more effective stays in hospital, and policlinic (policlinic services are a place where healthcare services can be accessed without the need for an overnight stay in hospital, usually such clinics are located close to a hospital) treatment and care, not all older persons manage to take care of themselves. The findings suggest that nurses should pay more attention to these patients' needs for care at different levels of the healthcare service.

\section{Introduction}

Approximately ten percent of the global pop- ulation are 60 years of age or older and this proportion is expected to double by $2050 .{ }^{1}$ This pattern of aging is also evident in Norway. The number of fragile older people will increase in line with the aging population. With increased age comes an increased risk of lower quality of life along with age-related symptoms and diseases. In Norway ${ }^{2}$ as in other Western countries, ${ }^{3}$ rural areas tend to have a higher percentage of older individuals than urban areas do and as life expectancy increases, the challenge of providing integrated end-of-life care also increases. ${ }^{4,5}$

According to the Norwegian National Cancer Register, the majority of people suffering from cancer are 65 years of age or olde. ${ }^{6}$ Based on a growing body of literature that describes older adults' desire to live in their own homes and neighbourhoods until death, the Norwegian healthcare system's political ambition is that cancer patients, regardless of age, shall be given the opportunity to live independent and active lives in their own homes for as long as possible.

In order to provide medical assistance without hospitalising the patients, outpatient treatment and policlinic services play an important role insofar as they constitute a place where healthcare services can be accessed without the need for an overnight stay in hospital (such clinics are usually located close to a hospital) To ensure the quality of care and outcome for the patients, close collaboration between the community's healthcare services and the hospital is necessary. ${ }^{7}$ From a nursing perspective, this requires a proper infrastructure of communication and awareness of each service's respective responsibilities.

The municipalities are responsible for all primary healthcare services in Norway. Some municipalities have employed specialist oncology nurses to coordinate cancer care ${ }^{8}$ and a collaborating network of resource nurses has been established within all four health regions to facilitate coordination between hospitals and communities. ${ }^{9}$ Fragmented healthcare and poorer patient outcomes are recognized as being a challenge for people living in rural areas all over the world. ${ }^{10-12}$ For example, studies show ${ }^{13}$ that effective rural healthcare cannot be delivered through urban treatment centres, that is, centres similar to those used in Norwegian policlinic care. Rural patients also receive lower levels of preventative care and have fewer meetings with physicians and specialists. ${ }^{14}$

In Norway, as in other countries, people who reside outside urban areas with palliative treatment services must commute to gain access to such services. However, little is known about the experience of commuting for care $^{4}$ and being forced to leave one's home community for care can be stressful, even for those in the early stages of the disease. ${ }^{15}$ It is
Correspondence: Ove Hellzen, Faculty of Health and Science, Nord-Trøndelag University College, Namsos, Norway. E-mail: ove.hellzen@hint.no

Key words: commuting, content analysis, older people, nursing, policlinic palliative care.

Acknowledgements: the authors would like to thank the patients whose participation made this project possible. We are also grateful to our colleagues at the Faculty of Health and Science, Nord-Trøndelag University College for their helpful advice and constructive criticism.

Contributions: GBW, $\mathrm{OH}$, study design; GBW, data collection; GBW, SD, $\mathrm{OH}$, analysis; GBW, SD, $\mathrm{OH}$, manuscript preparation; GBW, SD, literature review.

Conflict of interest: the authors report no conflicts of interest.

Received for publication: 11 April 2011. Accepted for publication: 11 July 2011.

This work is licensed under a Creative Commons Attribution 3.0 License (by-nc 3.0).

(C) Copyright G.B. Wiik et al., 2011

Licensee PAGEPress, Italy

Nursing Reports 2011; 1:e3

doi:10.4081/nursrep.2011.e3

also recognised that older adults in rural areas are at risk of not being able to continue to live at home because of decreased physical and mental health status. ${ }^{16}$ In rural areas, they are at an additional risk because of the distance between people and healthcare facilities that can result in geographic isolation. Even though they may be more dependent on public healthcare services, people in rural areas are more likely to use informal support than those in more urban areas. ${ }^{17-19}$

A review of this field therefore reveals a lack of knowledge about how older adults living in rural locations suffering from severe cancer experience palliative care in an outpatient setting. It is also not known how those in the advanced stages of cancer, who commute to urban treatment centres for care, perceive their situation. Therefore, the current study was undertaken to shed light on the experience of these patients in a Norwegian context.

\section{Aim}

The key aim of this study was to find out how older people diagnosed with incurable cancer managed and coped with their experiences of commuting for palliative care. 


\section{Materials and Methods}

A case study approach was chosen for this study to explore the informants' uniqueness and commonality in the context of research focused on the informants' real-life context, a context over which the researchers had little control.

\section{Study design}

The case study approach used a naturalistic, qualitative methodology to explore the individual and combined experiences of five, single older individuals who had cancer. Naturalistic inquiry is grounded in the belief that knowledge can be developed inductively using methods that are emergent and flexible to change. ${ }^{20}$ Unique cases could be identified as a way to understand the phenomenon of interest. A study based on particular cases must be seen as microscopic and not representative in itself. Therefore, the challenge lies in the researcher's ability to locate the global in the local. ${ }^{21}$ According to Giddens, this is possible by investigating and comparing several cases. ${ }^{22}$

\section{Data collection}

The study comprised five older persons suffering from incurable cancer and who were receiving life-prolonging chemotherapy. The inclusion criteria for the study were that the participants had to be older than 65 years of age, live in a rural area (i.e., in a community with less than 3000 inhabitants or a maximum of eight inhabitants per $\mathrm{km}^{2}$, a definition based on the Norwegian Government's Plan, No. 02, 2004 Ruralitet og urbanitet - bygd og by), live alone in their own home, have at least 90 minutes of one-way travel between home and the hospital, be receiving chemotherapy as a palliative treatment, and have a diagnosis of cancer. Contact with eligible patients was mediated through nurses in an oncologic policlinic at a local hospital. Patients who met the inclusion criteria were informed orally about the study and were given more information about the purpose and method by letter if they wished to participate. Interested individuals were encouraged to contact the researcher (GBW) by telephone or mail. The researcher met each volunteer and informed them orally about the study. In conjunction with this meeting, each participant was given a letter that informed them that participation was voluntary and that their contributions would be kept confidential and unidentifiable. Written informed consent was established.

Afterwards, the participants were again informed by the researcher of the purpose of the study and they were given the opportunity to talk to a psychologist if they felt troubled as a result of the information they had imparted.
The participants chose to meet the researcher in their own homes. There were no drop-outs. The regional research ethics committee of Mid-Norway approved the study (No. 4.2007.1149). A summary of the participants is given in Table 1.

The interviews were conducted as conversations. The interview questions were formulated so that the relevant information on the subject could be obtained, yet the questions were flexible enough to allow the participants to respond and participate easily, thus encouraging them to share their thoughts and feelings. ${ }^{23}$ As additional information, direct observations were made in conjunction with the interviews. Notes were taken and impressions were written down and summarized immediately after the interview in an observational protocol. Observations of body language and other gestures were considered to be useful as clues for the analysis. Additional observations gave details about the person's social and physical environment and coloured the context of the cases. ${ }^{24}$

Interviews and observations were conducted by the first author (GBW) and were carried out according to the participants' preferences as regards place and time. Each informant was asked to speak (narrate a story) about the following themes: (i) what they think is important and what gives them strength to manage their daily lives; (ii) their experiences of living with cancer; and (iii) their thoughts about and experiences of chemotherapy and the trip to treatment and back home. Using stories as a data collection method is supported by Sandelowski who feels that an individual's story gives important information about the person who narrates (we are the stories we tell) and that a story includes, in itself, the past, present and future. ${ }^{25}$

The interviewer tried to interrupt the participants as little as possible to give them an opportunity to tell their story in their own words and concentrate on what they felt was important. The goal was to help the informants to keep an accurate perspective of time and relevance to the questions by means of brief comments. Apart from that, the researcher tried as far as possible not to be invasive. The interviews lasted from 55 to 125 minutes and were tape-recorded and transcribed verbatim within one week of the interview.

\section{Analysis}

Because of the use of different data collect ion techniques a common problem during case study research is the large amount of collected data. ${ }^{26}$ However, it is important even at the analysis stage to have the final reporting of the results in mind in order to reach optimal readability of the study results. ${ }^{23}$ The purpose of the analysis was therefore twofold: firstly, to describe the message in the texts and second- ly, to identify a structure for the presentation and readability of the interview texts.

Five people older than 65 years of age who had been diagnosed with incurable cancer told stories and imparted their thoughts on and experiences of how their cancer had influenced their lives. The transcribed interview text and observational protocols were analysed using content analysis inspired by the work of Krippendorff ${ }^{27}$ and Graneheim and Lundman. ${ }^{28}$

The analysis was performed in several steps. In order to gain an overall picture several open readings were done. Meaning units, consisting of a word in a sentence or several sentences bound together, were identified and coded to reflect the content they represented. ${ }^{28}$ The three themes guiding the interview were used to search for patterns that could describe the participants' everyday life and their experiences of receiving treatment and care. Observational notes from each interview were then reviewed and collated to the contents identified. Each new interview was compared with the previous ones in order to confirm or disconfirm findings. ${ }^{23}$ The various codes were compared and, depending on their content, sorted into sub-categories. Based on the logical content, the sub-categories were compared, sorted, and abstracted into three final categories describing contents present in all five cases.

In the analysis it is important to have is in mind that it is each individual case that are in focus. Therefore, it must be analyzed with a sense of correspondence, that is, to understand observations and narratives with regard to each case and how well the path of interpretation give each case justice and answer the research question. ${ }^{26}$

To achieve trustworthiness for the study, all authors were involved in the data analysis. All authors read the interview texts and observation protocols but the codes were sorted and categories and sub-categories were derived by the first author (GBW). The second and third authors (SD and $\mathrm{OH}$ ) read the transcripts while following the path of the analysis. In addition, repeated discussions took place between the authors about the level of abstraction and the interpretation of the findings until consensus was reached. ${ }^{24}$

\section{Results}

The analysis revealed three main categories representing the findings in all five cases: Hovering between hope and fear, Stressful commuting to palliative care, and Being exhausted. One example of the analysis is given in Table 2. The study narratives must be seen as complex because there are several factors that influence the informants' everyday lives: the 
disease itself and its treatment, they all live alone, they all experience stress and insecurity and they all live with hope for a better daily life. At the same time, they are all unique with unique life histories. All the narratives are very moving, told by individuals in severe life situations characterised by both hope and despair. The informants' general health was influenced to a varying degree, for example, by fatigue and a decrease in weight. At the same time, they all expressed great hope and expectations as regards chemotherapy and a better daily life. Their will to live and desire to be at home and take care of themselves were important and strong features of them all. None expected or wished for home follow-up by the formal healthcare providers.

The results are presented in summaries of each informant's narrative below. This way of communicating findings emphasizes the importance of the context, and places the results in the informant's real world. The informants have been given fictitious names.

\section{Anni}

Anni lives alone in her own house, located outside a small village. She has been widowed for several years and has three adult children with their own families who live in other parts of the country. She has no family that is geographically close so a neighbour helps her with practical work such as firewood and transportation to the market. Anni suffers from a bad knee in addition to cancer. She was diagnosed with stomach cancer three years ago.

\section{Hovering between hope and fear}

Anni began her story by talking about her family and how much they mean to her. She said that the telephone is her link to them. She also praises her neighbour and emphasizes that she regards him as her mainstay in practical everyday life. During the last two years, Anni has experienced being one with the disease because of complications that have led to several stays in hospital. When talking about this two-year period, she said that she was often afraid but that the hospital staff had given her hope.

Today, chemotherapy is Anni's hope. At the time of the interview, she had received five treatments over the previous two and a half months. She thinks chemotherapy is good. She said, It's great. It gives me hope. Except that I don't know how good it is. Anni is uncertain about the treatment's effect and said that she is thrown between hope and despair. During the interview she often gave a positive picture of it but equally often she talked about her uncertainty about chemotherapy. She said, I am really looking forward to getting my sense of taste back. How good it will be...to experience the taste of food again... I am really looking forward to that... if I get better. I don't think about it so much. I take every day as it comes.

\section{Stressful commuting to palliative care}

During the interview Anni talked about her many trips to the hospital and raised her voice when talking about the taxi trips. She said, Sometimes I have to wait for a couple of hours for a taxi. That's the worst part... it's annoying, I don't know anything. They have to fill up each taxi with passengers before they start the trip...therefore it's a long wait. I can't understand what our politicians are thinking about...I think a lot about that. On days when Anni goes to the hospital, she has to get up before 7 a.m. and her neighbour comes over and fixes breakfast. The taxi trip takes two hours and Anni is usually already tired when she gets to the hospital.

Anni describes the time at the hospital as great. She said that the oncologic policlinic is a place where she can relax and that its staff members are great. When the treatment is finished, she often has to decline lunch because she does not know when the trip back home will start. It depends on how quickly the taxi fills up with passengers. Anni said, I buy a cake at the sweet stall before I go back home. Usually the taxi is filled up. Last time there were three of us sitting in the backseat.... I was especially

Table 1. Summary of participant background.

\begin{tabular}{|c|c|c|c|c|c|c|c|}
\hline Name & Gender & Age & Marital status & $\begin{array}{l}\text { Distance from } \\
\text { own home to } \\
\text { hospital }\end{array}$ & $\begin{array}{l}\text { Travel time between } \\
\text { home and hospital with } \\
\text { car (one way) }\end{array}$ & Means of travel & Daily network \\
\hline Anni & Female & 79 & Widow & $120 \mathrm{~km}$ & 120 minutes & Bus and train & Neighbour \\
\hline Ben & Male & 77 & Unmarried & $165 \mathrm{~km}$ & 150 minutes & Car and boat & None \\
\hline Clara & Female & 78 & Widow & $170 \mathrm{~km}$ & 150 minutes & Bus & Son with family \\
\hline David & Male & 79 & Unmarried & $90 \mathrm{~km}$ & 90 minutes & Car & Brother \\
\hline Emmi & Female & 70 & Widow & $200 \mathrm{~km}$ & 180 minutes & Bus and boat & Daughter \\
\hline
\end{tabular}

Table 2. Example of analysis.

\begin{tabular}{|c|c|c|c|}
\hline Meaning units & Code & Sub-category & Category \\
\hline $\begin{array}{l}\text { It's difficult to explain...//... you see there have been a lot of down } \\
\text { periods during my disease. At times, I have thought I have been outside } \\
\text { myself...//... I was better during one period but then it came back ... } \\
\text { and life has collapsed again... yes, it has been hard during the years. } \\
\text { I often think I cannot mange anymore... I cannot give up. It's like a nightmare } \\
\text { but I have to fight... I have to fight against it. }\end{array}$ & Divided & $\begin{array}{l}\text { Living with insecurity } \\
\text { and inner strength }\end{array}$ & $\begin{array}{l}\text { Hovering between } \\
\text { hope and fear }\end{array}$ \\
\hline $\begin{array}{l}\text { It is quite a distance to the hospital. I start my trip about 7:30 in the } \\
\text { morning and arrive at the hospital about 11:30. I get my treatment } \\
\text { around } 12 \text { o'clock. The bus back home starts at } 5: 30 \text { in the evening... } \\
\text { I have to change buses... then I have to wait an hour for the other bus... } \\
\text { I'm home after } 11 \text { pm. I'm exhausted when I come home... } \\
\text { Last time, it almost went wrong. On the ferry I had to lock myself } \\
\text { in the toilet and I vomited during the whole ferry trip... }\end{array}$ & Travelling & $\begin{array}{l}\text { Travelling to the hospital and } \\
\text { back is an extremely } \\
\text { strenuous activity }\end{array}$ & $\begin{array}{l}\text { Stressful } \\
\text { commuting } \\
\text { to palliative care }\end{array}$ \\
\hline $\begin{array}{l}\text { The first day after the treatment is okay. Then I'm elated. } \\
\text { Then I become enervated and listless... } \\
\text { I want to do something but then I'm too tired. I'm so tired... }\end{array}$ & Fatiguing & Feeling worn out & Being exhausted \\
\hline
\end{tabular}


stressed out because I felt nauseous...but I didn't throw up. When she finishes the trip and is back home, she feels much better. Even though she is exhausted, she said she feels great. She said, I'm totally worn out when I'm back home. I have to lie down on the sofa with my feet up. I stay there, on the sofa, for some hours.... When I get back, my neighbour has always made lunch and a fire in the iron stove...so it's warm at home. It's nice to be home, it's nice to leave the hospital.... I really do like that.

\section{Being exhausted}

Anni's life at home is strongly influenced by the fact that she is exhausted and does not recover between the treatments. She is planning to ask permission to extend the period between the treatments to three weeks instead of two. When describing her everyday life she said, If only I could escape the exhaustion. I'm so exhausted... you see, I used to manage myself... before I got ill I always needed something to do. Nowadays I'm always tired. Anni's experience is that the first day after the treatment is okay but the rest is hard because she becomes more and more exhausted until it is time for the next treatment. However, she says she can stand the exhaustion; the most important thing is that she is at home.

When Anni reflects on her everyday life she says, I have some pain but I shouldn't complain. It's my poor appetite... and the pain in my mouth. I'm so exhausted... Maybe it's because I have pain in my feet... I wonder why I have this pain in my feet. They go numb... it's like walking on pillows... sometimes I don't feel my feet at all. Anni's weight loss and bad appetite worry her. She has lost 16 kilos, from 80 to 64 , since she became ill and she describes herself like this, My watch dangles around my wrist and my clothes are too large. However, she gets a lot of support from her neighbour, about whom Anni said, He says I have to eat more... it's just a matter of opening my mouth and swallowing... He says that if he didn't fix my meals, I would starve to death... It's like this: if I have no longing for food, I don't cook; I don't prepare any meal.

Anni has no help from formal care providers between treatments. She has no trust in the district medical staff. Her experience is that the physician does not understand her situation and the district nurse who visited her to dress a sore had no time or interest for anything else. Anni said, I haven't asked the nurse so much... I haven't... a nurse seldom visits me.

\section{Ben}

Ben was a fisherman before he got cancer. He had his own boat that has been sold. Ben lives in his own house in a small village. He is unmarried and has no children, but he has a brother and a nephew in the neighbourhood whom he sometimes visits. Ben has suffered from intestinal cancer for one and a half years.

\section{Hovering between hope and fear}

In his story, Ben focuses on his own negative experiences of formal care and reflects on how Norwegian society takes care of its older residents. He becomes emotional when he talks about his feelings and the uncertainty of living with cancer. He emphasizes his struggle to be believed by the professional care providers; in his opinion, he suffered from cancer for several years before he was diagnosed. He tells about his first meeting with formal care services. According to Ben, the district medical officer accused him of eating bad... rotten food and so on; Ben left the first meeting without any clear measures from the physician. Ben did not recover. He became nauseous and revisited the health station where he was told that the physician was not there. Ben said, I'm not easy to get rid of so I sat down and waited... and then the physician came out from his office. He was a good lad and I was glad it wasn't the first physician I met. He asked me what was wrong and I said that it was the devil that had stroked my stomach. Ben raises his voice and hits his hand on the table when he talks about his meeting with formal care providers and his struggle to be believed. He emphasizes the importance of never giving up. Ben said, Yes, you have to fight, otherwise it goes to hell... In the end, it's a question of the patient's health. It looks likes the physicians have learnt from the veterinaries that if they don't recover within a few days, it's better to shoot them. It's active euthanasia... I feel like rubbish... It seems I haven't deserved the treatment.

After he was diagnosed with cancer, Ben went through his first intestinal surgery. After a short period at home, he was readmitted to the hospital for further extensive surgery, where they observed metastasis. He talks about a new medicine that he has not been prescribed. He said, I think it's strange that they don't give help to an old person... I have heard something like that... I'm too old, I have no value, and it's not worth investing in me. Ben feels that his health is bad and that he is becoming more ill every day. He is uncertain when his palliative treatment will end, but when he becomes well again, he plans to go on a fishing tour with his nephew. This is his hope, what he longs for. At the same time he talks about his suffering. Ben said, If I just sit here waiting, then I start regretting the surgery that I went through. The worst thing is to wait for the end to come... that's no life. It would have been much better to get into the boat, go fishing... and had it gone wrong out there on the sea... at least that would be a quick death.

\section{Stressful commuting to palliative care}

During the interview Ben talked about his trips to the hospital. He chose to travel to the hospital for his chemotherapy treatment at the oncologic policlinic by boat instead of taxi. He explains why: The best thing with the boat is that I do not need to go by taxi... all over the country... They collect people and drive around the whole countryside, you know, on small roads... it's like being stabbed with a knife in the stomach. No, I can't cope with that anymore... it takes more than four hours one way... I'm glad I can take the boat.... that's the best way to travel. Ben says he gets up at 6 a.m. and the ferry goes at 8 a.m. He has organised his treatments so they match the ferry schedule, and he is back home at about 11 p.m. He says that his last trip home after the treatment was painful. When I went back last time it was windy... you know, a high sea with big waves. So I didn't manage to take my bag from the boat... I was too exhausted... I had to ask for help to cross the gangway. At last I came to the car and could go back home.

\section{Being exhausted}

Ben receives chemotherapy every other week. He is marked by his disease and has lost 25 kilos since he was diagnosed. According to him, he has no follow-up from the formal municipal healthcare service, something he does not miss. During the interview, Ben talked about his everyday life which is characterised by hospital trips, dizziness and exhaustion. He said: "I'm so tired... I don't know why I feel like this. As patients we are not allowed to know anything and that... that makes me angry. I don't think there is anything wrong with my brain, I think I have a lucid mind..." When he comes home after a bout of treatment, he just watches TV and rests. If he has the strength, he cooks, but usually he has no appetite. He says his weight loss worries him. Ben said, I look at my watch and eat half a slice of bread now and then, but the food grows in my mouth... I must eat... I'm so thin and miserable. His exhaustion makes his daily life a problem. For example, he does not have the energy to clean the house. Ben said, During the last few years I haven't been man enough to go out with the boat and fish. You know, it was my life... I have sold my boat, but it would be nice if I managed to go out fishing... once more.

\section{lara}

Clara lives alone in her own house. She has been a widow for many years. Her house is situated in the countryside, about 2 hours from the hospital. She has grown-up children and her house is next to her son's home. She was diagnosed with intestinal cancer one year ago.

\section{Hovering between hope and fear}

When Clara talks about her life with cancer, she starts with the time before she was diagnosed with cancer. She said she had problems with her stomach long before she knew about 
her disease and that the formal care providers did not believe her when she complained about pain. She is glad that she has been prescribed chemotherapy. She looks forward to finishing it and being cured. At the same time, Clara emphasizes that life with chemotherapy is hard. She feels exhausted both physically and mentally and she has difficulty planning her future. Living with cancer means living in a state of uncertainty. Clara said, I don't know the risks of a relapse, nor what shape I will be in next month. It doesn't matter...I don't know whether I'll be alive next month.

Suffering from cancer means a trying everyday life. Clara talks about a female friend who had cancer and suffered a lot of pain before she died. Clara cries when she talks about her friend. She said, Hopefully my family won't need to experience my life ending up in such a way. I will spare them from that. My friend had severe pain in her feet... I have pain there too. Clara is relieved to speak about her cancer and life situation, relieved to have someone who listens to her. She thinks that it is hard for others to understand her situation and what she has gone through. Even though the disease means a hard everyday life, she emphasizes the importance of being cheerful. Clara manages to stay in good spirits, and together with a large circle of friends who support her, life is acceptable. The support given by her family is especially important. She said, I'm privileged... one has to be grateful for what one has in life.

\section{Stressful commuting to palliative care}

At the time of the interview, Clara had had six treatments. She does not know how many more she must go through. She praises the oncologic policlinic staff for their support and competence. Clara says that the most trying thing with the chemotherapy is travelling to the hospital and back home. She gets up at about 5 a.m. and the taxi picks her up at 6 a.m. She said, I'm so enervated and exhausted... but one must try. The chemotherapy takes about five hours. Usually the taxi is filled with other passengers before going back home. Clara said, The trip home takes a long time. You know, they try to save money.... Sometimes we have to change taxis half-way. It can take more than three hours. In the winter the roads are slippery... luckily I don't get carsick.

\section{Being exhausted}

To be in her own home is important to Clara. She said, The most valuable thing for me is that I can still dress myself... and be at home. She thinks she is coping well with chemotherapy. She has a good appetite and seldom has nausea. Despite this, she has lost 12 kilos. It is the exhaustion that is the worst; it influences her social life negatively. She said:"I think they take it for granted that I manage my daily life well... but I'm so exhausted. I never find peace to rest...

\section{David}

David lives alone in his own house. He has a younger brother who lives in a house beside him but he has no other family. The two brothers have cultivated the farm together but since David's diagnosis, his brother does it alone. He was diagnosed with cancer six months ago. It began with stomach pain and weight loss.

\section{Hovering between hope and fear}

At the time of the interview David was seriously ill. However, he insisted on carrying out the interview. David began his story by talking about his surgery and the time after surgery, which was very painful. Now he pins all his hope on chemotherapy. He said, Suffering from cancer is like living on borrowed time. He talks about the suffering connected to the disease and refers to his mother who died from cancer. He said, She suffered, poor woman... and how thin she became... but she didn't get any help. It's better today. I have lost a lot of weight myself. I can't eat that much. Food doesn't taste like anything...my trousers have become too large. Perhaps everything will get better when I have finished the treatment.

\section{Stressful commuting to palliative care}

To live with chemotherapy means hope. David says they told him at the hospital that he prolongs his life if he accepts the chemothera$p y$. David said, I do it for my brother. I think he needs me. Like the other informants, David describes the policlinic staff as being kind and competent. His brother takes him to the hospital so he does not need to take a taxi. He is grateful for this because he feels exhausted and in bad shape.

\section{Being exhausted}

David thinks his exhaustion is the worst thing about the cancer. He does not have the power to do things by himself. He depends on his brother, who helps him with his daily life. For example, his brother is the one who cooks. David said, I don't ask him about it, he just does it. So, I'm happy with that... it's a miracle that he learned to cook. Even though David accepts that he needs help, he smiles when he thinks about the role change he and his brother have performed. He does not like to burden his brother. He said, It's a pity that my brother has to struggle for me. Springtime is the most hectic period in a farmer's life. I ought to help him... now he has to do everything on his own... poor him.

\section{Emmi}

Emmi has been a widow for 10 years. She lives alone, but her two daughters and her son live nearby with their families. Emmi was first diagnosed with cancer nine years ago. She went through extensive treatment and was free from cancer until six months before the interview, when she was diagnosed with cancer again.

\section{Hovering between hope and fear}

Emmi talks about the time after her first cancer diagnosis and how she handles her everyday life. She is emotional when she narrates her experiences but mostly she talks about her good days and her positive everyday life with cancer. She begins by talking about how shocking it was when she got her first cancer diagnosis. She became ill the year after her husband's death. First, she was diagnosed with uterine cancer and underwent an operation for it. Three years later Emmi got a new diagnosis, this time a brain tumour. The second time round, the cancer was especially exhausting; she had to act so the physician would believe her. The worst is that she found that she must fight for optimal treatment. She said, You see, I was afraid to be just left sitting...for me it was like a nightmare and I thought to myself - I must fight. I was so angry and I contacted the patients' ombudsman. My impression was that people over 60 had no value. If they got cancer they should die. I thought the staff was so unfeeling and indifferent. Emmi received chemotherapy and regained her health. She followed the rules strictly and felt safe when she got a follow-up by a gynaecologist and a neurologist. Emmi had some good years until she relapsed six months ago. She talked about her trying situation in relation to her previous disease, especially in connection with different medical check-ups.

To wait in a state of uncertainty is the worst thing and she admits she is often afraid. But the next moment she emphasizes that she is used to the situation now and says that she does not know how she would react if someone told her that she had recovered. Emmi thinks that this is a strange feeling. She often wonders where she gets her inner strength from. She said, You see, there have been a lot of down periods... at times, I have thought I have been outside myself... as if I walked beside myself. Each time I have coped with the situation even though it has been hard... and suddenly it, the cancer, appeared again and my life has fallen apart again. Despite her story she says she has hope and zest for life. She hopes chemotherapy will give her a good life and more happy days. She thinks a lot about her childhood with its happy moments and finds consolation in the sea. She said, Just looking out over the sea is wonderful. It gives me strength.

\section{Stressful commuting to palliative care}

Emmi lives in another county. Therefore, she must finance her trips to the oncologic 
policlinic herself. Emmi said, Hell came the day we found oil here in Norway... nowadays we cannot afford anything, we have no money for anything anymore. I don't have the strength to change hospitals. The trips for treatment are hard for her because she often ends up with nausea. Last time, when I was going home it almost went wrong... On the ferry I got nausea and had to lock myself in the toilet... I vomited during the whole ferry trip. The whole trip, in both directions, takes more than 15 hours. In addition to the ferry, she goes by bus because she cannot afford a taxi. She starts at 8 a.m. and is home at 11 p.m. Despite this exhausting travel she does not wish to stay at the hospital overnight. She has never thought about doing that. Every time she finishes a bout of treatment she thinks she must go home as quickly as she can.

\section{Being exhausted}

Once home, Emmi is exhausted after the treatment and she is unable to do much. She takes the day as it comes and says that she does not do much. What worries her is her weight loss, but she tries to eat even though her appetite is not that good. She said, My mouth is like sandpaper... I hope it ends soon. It's not strange - my body is being filled with poison.

\section{Discussion}

When reading this paper it is important to remember that the findings presented are just one of many possible interpretations and that the present study is not an attempt to evaluate formal care. The data are based solely on our informants' personal experiences and are discussed strictly from their perspective. The intention of this paper is not to generalize the findings and interpretations, but simply to illustrate the complexity of the experiences of cancer sufferers. In this multiple-case study, the intention was to describe the experiences of five people diagnosed with incurable cancer, living alone in rural areas and undergoing outpatient treatment, with a strategy to search for meaning in any patterns that emerged in the interviews.

In recent decades, starting with the hospice movement in the 1960s, improvement of the care of the dying has become a matter of increased interest ${ }^{29}$ and palliative care has evolved from a hospice care philosophy. ${ }^{30}$ Although most cancer patients in palliative care have undergone traumatic treatment with a cure as the main goal, palliative care's main goal is quality of life. Palliative care has increasingly being referred to as a fundamental human right ${ }^{31}$ but there is still a need to increase knowledge and understanding in order to meet the unique needs of people living in rural communities.

The narrative stories of participants further suggest that older people who suffer from incurable cancer and who live alone in rural areas have to walk the palliative path alone and have to rely on informal support to a great extent. ${ }^{32}$ As Robinson et al. state, the question of the experiences of patients commuting from rural areas for policlinic palliative care is a neglected one. ${ }^{4}$ Although commuting is a regular part of a rural lifestyle, the situation is different for these patients. Indeed, the informants reported being tired and worn out, something they have in common with other cancer patients but in, the commuting that has to be done today could be seen as a factor that increased the informants' exhaustion. All informants talk about arduous and trying commutes for treatment, trips that could be seen as being energy drainers and which may in fact contribute to infections and a deteriorating state of health. ${ }^{33}$ Commuting for policlinic palliative care is one of the compromises they have to make for living at home, that is, to live in a place that contributed to their overall health. Although this raises questions about how commuting influences the informants' overall quality of life, it is important to remember that our informants pin a great deal of hope onto chemotherapy. ${ }^{34}$ Further research is needed to increase the understanding of how commuting influences the sufferers' wellbeing.

Parallel with exhausting round-trips for policlinic care, the informants describe a huge loss of weight connected with loss of appetite. Studies have shown that people living in rural areas have significantly less support from formal care providers than those living in urban settings ${ }^{13,35}$ and therefore have to rely on informal support to a greater extent. ${ }^{17}$ These findings are similar to ours, indicating that the informants are not happy with the formal care services and get little support from them. According to Selman et al., among others, it is important that people suffering from cancer get support from formal care providers to help them walk the palliative paths. ${ }^{36}$ For example, there is a need for improved training opportunities for community nurses in rural areas, training that would help nurses improve their skills and create optimal meetings with their patients. ${ }^{37}$ In the present study, it is obvious that the informants have to carry most of the responsibility for their own health and wellbeing themselves.

Previous research ${ }^{38}$ indicates that meeting patients' need for information in a timely and appropriate way is a key concern of palliative care. In this study, the informants' experience was that they were abandoned between the policlinic visits. This was obvious with regard to our informants' huge weight-loss and the fact that all of them ran the risk of becoming undernourished and therefore also ran an increased risk of complications. The informants had no one to inform them about subjects connected to cancer, except the policlinic staff. According to Selman et al., not being given necessary information is related to patients' anxiety about the disease and the future. ${ }^{36}$

\section{Methodological considerations}

When recruiting people with incurable cancer who receive palliative treatment, there were some difficulties as regards whom to include. Since informants were recruited on the basis of recommendations from the oncologic policlinic and not through the researchers' own knowledge, there was a risk that the participants' experiences would not fit with the aims of the research. However, even though only five older people were interviewed and observed, it became obvious during the interview that all participants would be able to share experiences relevant to the research. Each informant's experience presented a unique opportunity to learn what it is like to be an older person suffering from incurable cancer and living alone in a rural area. Their contribution represented both uniqueness and a range of characteristics and experiences, and their responses were linked to wider existing literature. The strategy was to search for meaning in the patterns that emerged. According to Yin, a case study design is wellsuited when the purpose of the research is to describe the holistic and meaningful aspects of real life events. ${ }^{23}$

In this multiple-case study, our intention was to mediate the experiences of the rural older people suffering from incurable cancer in a descriptive way. Our decision to choose five cases in this multiple-case study was based on the question of representativeness and what the cases intended to explain. As Hamel said, even if the number of cases is a significant factor.../l...no investigation can be defined on the basis of that issue alone. ${ }^{22}$ As long as a sufficient number of cases in the study are wellconstructed, it is possible to see the microscopic (local) as macroscopic (global) and therefore determine the study's representative value.

\section{Conclusions}

This multiple-case study gives an on-thespot account of the experiences of five older adults living alone in a rural region and commuting for policlinic palliative care. Obviously, experiences may vary depending on factors such as the individuals themselves, geographical location, rural community and commuting 
distances. In our opinion, the representativeness of our five cases is satisfactory and is explained through the connection to existing literature.

The main finding of this study is our informants' situations: what they have in common is that they do not speak out and they do not complain, findings similar to Robinson et al., ${ }^{4}$ for example. Therefore, it is important to mediate their stories. The Norwegian government talks about the best treatment wherever you live, but our investigation shows that there is still a long way to go before those words are true. The trend is for more treatment to be centralized, becoming more effective with shorter stays in hospital, and be based mostly on policlinic treatment and care. Not all older persons manage to take care of themselves. Some live alone and are alone with their decisions. They think their problems come from cancer alone. However, in the course of this study it became clear that many factors influence their wellbeing. In their contact with these patients, nurses need to pay attention and show awareness of what they experience. By showing a more generous attitude and by clarifying options of care, nurses are important key holders to reduce distress in this situation. By trying to create a trustful climate when meeting the patients, nurses give them an opportunity to describe their life situation. In this way, nurses have the opportunity to understand the individual patient's unique situation. The findings also serve as a reminder of the importance of collaboration and communication between different levels of health services. Meeting needs and providing care wherever patients are means exchanging relevant information and making use of resources available.

This study is the first part of a larger study designed to focus on older elderly people who suffer from incurable cancer and who live alone in rural areas. To understand the special needs of people in rural areas, more research is needed to understand the meaning of their experiences.

\section{References}

1. Schoenmaeckers R, Kotowska I. Population ageing and its challenges to social policy Council of Europe. 2005. http://www.coe.int/t/e/social\%5Fcohesion/p opulation/Publications/ Accessed: 15 February 2007.

2. Statistics of Norway. Population Statistics. 2010. http://www.ssb.no/ Accessed: 14 October 2010.

3. Manthorpe J, Lliffe S, Clough R, et al. Elderly people's perspectives on health and well-being in rural communities in England: findings from the evaluation on the National Service Framework for Older People. Health Soci Care Commun 2008;16:460-8.

4. Robinson CA, Pesut B, Bottorff JL, et al. Rural palliative care: a comprehensive review. J Palliat Med 2009;12:253-8.

5. Robinson CA, Pesut B, Bottorff JL. Issues in rural palliative care: views from the countryside. J Rural Health 2010;26:78-84.

6. Norwegian National Cancer Register. Cancer in Norway, 2008. http://www.kreftregisteret.no/Global/26-012010\%20Dok\%20til\%20web\%20ferdig.pdf Accessed: 5 February 2011.

7. Ministry of Health and Care Services. The Coordination Reform. 2008. http://www.regjeringen.no/en/dep/hod/dok/ regpubl/stmeld/2008-2009/stmeld-nr-472008-2009-.html?id=567201 Accessed: 9 January 2011.

8. Ministry of Health and Care Services. National Program for Palliative Cancer Care (In Norwegian). 2007. http://www.shdir.no Accessed: 20 November 2010.

9. Ministry of Health and Care Services. National Strategy plan for cancer care 2006-2009 (in Norwegian). http://www.regjeringen.no/nb/dep/hod/tem a/sykehus/dette-mener-regjeringen/ aktuelle-planer-og-strategier/nasjonalstrategi-for-kreftomradet-2006-html Accessed: 20 November 2010.

10. Comer J, Mueller K. Access to health care: urban-rural comparisons from a midwestern agricultural state. J Rural Health 2008;11:128-36.

11. Mann L. From "silos" to seamless healthcare: bringing hospitals and GPs back together again. Med J Aust 2005;182:34-7.

12. Dixon J, Welch N. Researching the ruralmetropolitan health differential using the "social determinants of health". Aust J Rural Health 2001;8:254-60.

13. Goodridge D, Lawson J, Rennie D, Marciniuk D. Rural/urban differences in health care utilization and place of death for persons with respiratory illness in the last year of life. Rural Remote Health 2010;10:1349-64.

14. Friedell GH, Rubio A, Maretzki A, et al. Community cancer control in a rural, underserved population: the Applachian Leadership Initiative on Cancer Project. J Health Care Poor Underserved 2001;12:519.

15. Reif S, Golin CE, Smith SR. Barriers to accessing HIV/AIDS care in North Carolina: Rural and urban differences. AIDS Care 2005;17:558-65.

16. Buchner DM, Wagner EH. Preventing frail health. Clin Geriatr Med 1992;8:1-17.

17. Coward R, Cutler SJ, Mullens RA. Residential differences in the composition of the helping networks of impaired elders. Family Relations 1990;39:44-50.

18. Montoro-Rodriguez J, Kosloskiu $\mathrm{K}$ Montgomery RJ. Evaluating a practice-oriented service model to increase the use of respite services among minorities and rural caregivers. Gerontologist 2003;43:916-24.

19. Bedard M, Koivuranta A, Stuckey A. Health impact on caregivers of providing informal care to a cognitively impaired older adult: Rural versus urban settings. Can J Rural Med 2004;9:15-23.

20. Lincoln Y, Gruba EG. Naturalistic Inquiry. Newbury Park: Sage Publications; 1985.

21. Hamel J, Dufour S, Fortin D. Case Study Methods. Newbury Park: Sage Publications; 1993.

22. Giddens A. Against "micro" and "macro": Social and system integration. In: Giddens, A. The Construction of Society. Berkeley: University of California Press. 1984. pp. 139-145.

23. Yin RK. Case Study Research: Design and Methods, 3rd edition. Thousand Oaks: Sage Publications; 2003.

24. Patton MQ. Qualitative Evaluation and Research Methods, 3rd edition. Newbury Park: Sage Publications; 2002.

25. Sandelowski M. We are the stories we tell: narrative knowing in nursing practice. $J$ Holist Nurs 1994;12:23-33.

26. Stake RE. The Art of Case Study Research. Thousand Oaks: Sage Publications; 1995.

27. Krippendorff K. Content Analysis. An introduction to its Methodology. London: Sage Publications; 2004.

28. Graneheim UH, Lundman B. Qualitative content analyzing in nursing research: Concepts, procedures and measures to achieve trustworthiness. Nurse Educ Today 2004;24:105-12.

29. Saunders C. The evolution of palliative care. Patient Educ Counsel 2000;41:7-13.

30. Doyle D, Hanks GWC, MacDonald N. Oxford Textbook of Palliative Medicine, 2nd ed. Oxford: Oxford University Press; 1998.

31. Brennan F. Palliative care as an international human right. J Pain Symptom Manage 2007;33:494-9.

32. Bedard M, Koivuranta A, Stuckey A. Health impact on caregivers of providing informal care to a cognitively impaired older adult: Rural versus urban settings. Can J Rural Med 2004;9:15-23.

33. Cimino JE. The role of nutrition in hospice and palliative care of cancer patients. Topics Clin Nutr 2003;18:154-61.

34. Benzein E, Norberg A, Saveman BI. The meaning of the lived experience of hope in patients with cancer in palliative home care. Palliat Med 2001;15:117-26.

35. Cinnamon J, Schuurman N, Crooks VA. A 
method to determine spatial access to specialized palliative care services using GIS. Selman L, Higginson IJ, Agupio G, et al. Meeting information needs of patients with incurable progressive disease and their families in South Africa and Uganda: multicentre qualitative study. BMJ 2009;338:b1326.

37. Crawford GB. Palliative care on Kangaroo Island. Aust J Rural Health 2000;8:35-40.

38. Parker SM, Clayton JM, Hancock K, et al. A systematic review of prognostic/end-of-life communication with adults in the advanced stages of a life-limiting illness: patient/caregiver preferences for the content, style, and timing of information. $\mathrm{J}$ Pain Symptom Manage 2007;34:81-93. 